\title{
Simultaneous atmospheric correction and quantification of suspended particulate matter in the Guadalquivir estuary from Landsat images
}

\author{
MIRIAM CARPINTERO ${ }^{1}$, MARÍA JOSÉ POLO ${ }^{\mathbf{1}}$ \& Mhd. SUHYB SALAMA ${ }^{\mathbf{2}}$ \\ 1 Fluvial Dynamics and Hydrology Research Group, Andalusian Institute for Earth System Research, IISTA, \\ University of Cordoba, Spain \\ o32cargm@uco.es; mipolo@uco.es \\ 2University of Twente, ITC, Hengelosestraat 99, 7500 AA Enschede, The Netherlands
}

\begin{abstract}
Earth observations (EOs) following empirical and/or analytical approaches are a feasible alternative to obtain spatial and temporal distribution of water quality variables. The limitations observed in the use of empirical approaches to estimate high concentrations of suspended particulate matter (SPM) in the estuarine water of Guadalquivir have led the authors to use a semi-analytical model, which relates the water constituents' concentration to the water leaving reflectance. In this work, the atmospheric correction has been carried out simultaneously and the aerosol reflectance and backscattering coefficients of SPM obtained. The results are validated using in situ SPM data series provided by a monitoring network in the study area. The results show that the model allows us to successfully estimate backscattering coefficients of SPM in the estuary, differentiating clear and turbid water and using two $\varepsilon_{(4,5)}$. These considerations improve the value of $\mathrm{R}^{2}$ from 0.68 ( $\left.\operatorname{single} \varepsilon_{(4,5)}\right)$ to $0.86\left(\right.$ two $\left.\varepsilon_{(4,5)}\right)$ on 18 May 2009 . This method could be used as a preliminary approach to obtain SPM concentration in the Guadalquivir estuary with the limitations that the model shows for turbid waters.
\end{abstract}

Key words water quality; remote sensing; semi-analytical model; turbid water

\section{INTRODUCTION}

River and sea dynamics interact in estuaries, which are complex aquatic systems and are among the most important areas for sediment and nutrient exchange between oceans and continents (Contreras et al., 2012).Suspended matter is an environmental indicator of the state of water quality and affects its transparency, turbidity and colour. The study of water quality variables, such as suspended sediments, chlorophyll and dissolved matter, is a key tool for characterizing the quality and dynamics of these environments, especially when regulations upstream are a constraint for the equilibrium between fresh and saltwater.

Traditionally, water quality variables have been measured in situ using conventional techniques implying direct measurements of water quality and representing a high cost both in time and money, along with their restricted spatial and temporal domain. However, the employment of remote sensing sources following empirical and/or analytical approaches has become a feasible, fast and low-cost alternative for studying the spatial distribution of water quality variables. The use of empirical algorithms presents some limitations regarding the specific range of the concentration, the area and the time of year (Salama et al., 2012).

Carpintero et al. (2013) determined empirical local relationships along the Guadalquivir Estuary to obtain turbidity map series that could feed transport models of the system. However, the high range of turbidity values that can be found in the estuary, together with its high variability and extreme conditions over long periods, made it difficult to discriminate the turbidity regime over a threshold of 750 nephelometric turbidity units (NTU). In this sense, the employment of analytical methods that permit the derivation of water quality variables in widespread and inaccessible areas using a hydro-optical model, which relates the water constituents' concentration to the observed water leaving reflectance has intensified in the past few years and constitutes a feasible alternative to the direct empirical approach.

This current work analyses the use of a hydro-optical model for estimating suspended particulate matter (SPM) concentrations under conditions of a high turbidity and great spatial and temporal variability. For this purpose, the atmospheric correction has been carried out simultaneously and the aerosol reflectance and backscattering coefficients of SPM were obtained 
from near-infrared (NIR) reflectances in the Guadalquivir estuary using Landsat satellite images, thus extending their use in Mediterranean areas.

\section{MATERIAL AND METHODS}

\section{Study area}

The Guadalquivir River estuary (Southwestern Spain) stretches for $105 \mathrm{~km}$ between the Alcalá del Río dam, upstream, and the river mouth at Sanlúcar de Barrameda (Fig.1). The contribution of freshwater to the estuary is subject to intense regulation by the Alcalá del Río Dam, the lowest one of a dense reservoir network throughout the $47900 \mathrm{~km}^{2}$ contributing area, which blocks the tidal wave upstream. The sediments in the estuary are of a very fine texture due to the great length of the river and, mainly, to the extreme trapping efficiency of the dense reservoir network upstream, with an average value of $0.5-4.5 \mathrm{~g} \mathrm{~L}^{-1}$ for the suspended sediment range along the estuary with extreme values of up to $16 \mathrm{~g} \mathrm{~L}^{-1}$.
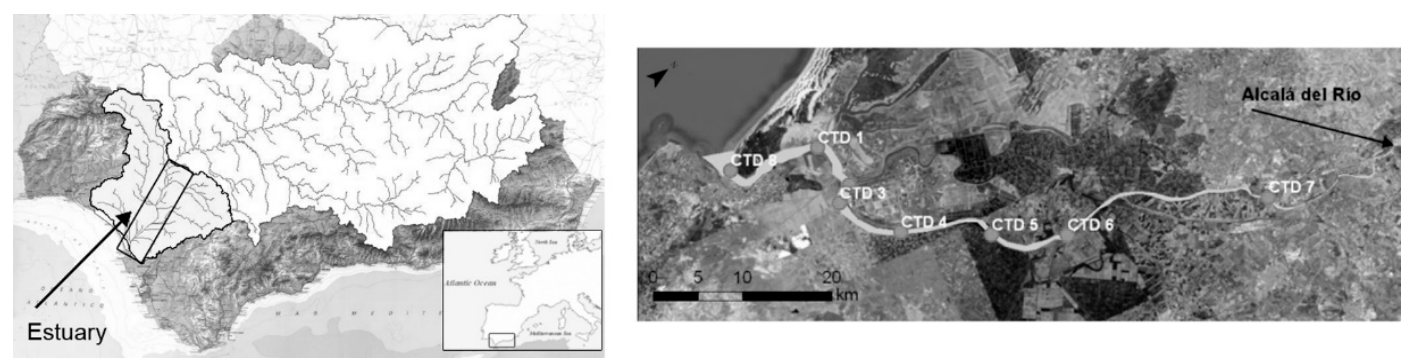

Fig. 1 Location of Guadalquivir River estuary and of the CTD buoys.

\section{Available turbidity data}

Continuous turbidity measurements were taken in situ every 30 minutes with eight turbidimeters (Turner Designs, model Cyclops-7) using CTD Seabird Electronics SBE16plus equipment with other external sensors along the Guadalquivir axis. These eight stations were installed on navigation buoys between the river mouth and Seville harbour, strategically positioned along the estuary, providing data from February 2008. The CTD number 2 was not used because there are no date for the study period. To obtain SPM concentration with this remote monitoring network, a relationship between SPM (measured by gravimetric method) and turbidity (NTU) was established (Navarro et al., 2011).

\section{Landsat -ETM data}

Thirteen Landsat Enhanced Thematic Mapper Plus (Landsat ETM+) images of scene 202-34 (path/row) were used from the period between 19 August 2008 and 25 August 2010; they were obtained from the US Geological Survey (USGS) Center (http://earthexplorer.usgs.gov/). The images were acquired on 19 August 2008; 23 November 2008; 25 December 2008; 11 February 2009; 31 March 2009; 18 May 2009; 23 September 2009; 9 October 2009; 29 January 2010; 3 April 2010; 5 May2010; 6 June 2010 and 25 August 2010. The selected images underwent a systematic correction to obtain the water leaving reflectance and backscattering coefficients, which are described below.

\section{Methodology}

Atmospheric correction. The total reflectance measured by the sensor at the top of the atmosphere (TOA) was obtained from the calibrated Digital Numbers (DNs). This total reflectance at a given wavelength $\lambda, \rho_{t}^{\lambda}$, can be written as the sum of several components (Gordon, 1997):

$$
\rho_{t}^{\lambda}=T_{g}^{\lambda}\left(T_{v}^{\lambda} \rho_{s f c}^{\lambda}+\rho_{a}^{\lambda}+\rho_{r}^{\lambda}+\rho_{r a}^{\lambda}+T_{v}^{\lambda} \rho_{w}^{\lambda}\right)
$$


where $\mathrm{T}_{\mathrm{g}}{ }^{\lambda}$ and $\mathrm{T}_{\mathrm{v}}{ }^{\lambda}$ are, respectively, the gaseous transmittance and the viewing diffuse transmittance from water to sensor; $\rho_{\text {sfc }}{ }^{(\lambda)}$ is the sea-surface reflectance; $\rho_{\mathrm{a}}^{(\lambda)}$ is the aerosol reflectance resulting from multiple scattering by aerosol in the absence of air; $\rho_{r}^{(\lambda)}$ is Rayleigh reflectance resulting from multiple scattering by air molecules in the absence of aerosol; $\rho_{\mathrm{ra}}{ }^{(\lambda)}$ is the reflectance from the interaction between air molecules and aerosol; $\rho_{\mathrm{w}}^{(\lambda)}$ is the water-leaving reflectance resulting from the interaction between the light and the water column. To derive the water-leaving reflectance, $\rho_{\mathrm{w}}{ }^{(\lambda)}$, all other terms of equation (1) must be quantified.

The standard approach by Gordon and Wang (1994) assumes zero water-leaving reflectance in the NIR $\left(\rho_{\mathrm{w}}{ }^{(5)}=0\right)$. The calculation of Rayleigh reflectance $\rho_{\mathrm{r}}{ }^{(\lambda)}$ is well described in terms of geometry and atmospheric pressure (Gordon et al., 1988a). The coupled term $\rho_{\mathrm{ra}}{ }^{(\lambda)}$ can be neglected at the NIR part of the spectrum (Gordon and Castano, 1987). Sea-surface reflectance, $\rho_{\text {sfc }}{ }^{(\lambda)}$, is estimated from the Fresnel reflectance equation. Gaseous transmittance $\mathrm{T}_{\mathrm{g}}{ }^{\lambda}$ is calculated from ancillary data on ozone and water vapour concentrations by using the transmittance models of Goody (1964) and Malkmus (1967). The diffuse transmittance $\mathrm{T}_{\mathrm{v}}{ }^{\lambda}$ is approximated following the model of Wang (1999). A detailed description of every step can be found in Salama and Shen (2010) and Salama et al. (2012).

Basically, equation (1) has two unknowns; the water-leaving reflectance, $\rho_{\mathrm{w}}{ }^{(\lambda)}$ and the aerosol reflectance, $\rho_{\mathrm{a}}^{(\lambda)}$. The Rayleigh corrected reflectance is computed from $\rho_{c}^{\lambda}=\rho_{t}^{\lambda}-\rho_{r}^{\lambda}-T_{v}^{\lambda} \rho_{s f c}^{\lambda}$.

Aerosol scattering reflectance, $\rho_{\mathrm{a}}^{(\lambda)}$, is directly estimated from the aerosol ratio at two NIR bands, $\mathrm{s}$ and 1 (s short, 1 long wavelengths), which can be related to aerosol optical thickness and type, and is considered to be constant for the whole image. Salama et al. (2004) suggested an automated approach to determine the aerosol ratio based on eigenvector decomposition of the NIR bands: $\varepsilon_{(s, l)}=\cot \left[0.5 \tan ^{-1}\left(\frac{C_{l l}}{C_{s s}-C_{s l}}\right)\right]$, where $C$ is the correlation between Rayleigh corrected reflectance of short band (s) and long band (l) of Landsat-ETM. In this work, this approach was applied to data from Landsat-ETM bands $4(837 \mathrm{~nm})$ and band $5(1625 \mathrm{~nm})$ (Danbara, 2014).Once the value of $\varepsilon_{(4,5)}$ is estimated, $\rho_{\mathrm{w}}{ }^{(4)}$ can be derived from equation (1), assuming $\rho_{\mathrm{w}}{ }^{5}=0$ in accordance with the standard approach:

$$
T_{v}^{(4)} \rho_{w}^{(4)}=\rho_{c}^{(4)}-\varepsilon_{(4,5)} \times\left(\rho_{c}^{(5)}-T_{v}^{(4)} \rho_{w}^{(5)}\right)
$$

It should be noted that this approach is not valid for high turbidity values (Kuchinkeet al.,2009) and a second parameter should be included as the ratio of water-leaving reflectances $(\alpha)$ at band 4 and 5, (Carder et al., 1999a,b). However, the great spatial variability of SPM in the study area, which is accentuated on certain dates coinciding with extreme turbidity events, makes it difficult to employ a spatially homogeneous $\varepsilon_{(4,5)}$ for the whole image. This variability justifies the fact that, at certain temporal moments, the problem is solved with different $\varepsilon_{(4,5)}$. In this work, different regions were identified in the corrected reflectance at band 4 versus corrected reflectance at band 5 plots to derive specific values for each group. The calculation of the $\rho_{\mathrm{w}}{ }^{(4)}$ for these areas is made not only using a specific $\varepsilon_{(4,5)}$ for each of them but also the most suitable algorithm.

Deriving water inherent optical properties $\rho_{\mathrm{w}}^{(\lambda)}$ is proportionally related to physical and biological water properties according to the semi-analytical model of Gordon et al. (1988b):

$$
\frac{\rho_{w}^{\lambda}}{T_{o}^{\lambda}}=0.54 l_{1} Q \frac{b_{b}(\lambda)}{b_{b}(\lambda)+a(\lambda)}
$$

where $\rho_{\mathrm{w}}{ }^{\lambda}$ is the water-leaving reflectance normalized to the solar transmittance from sun-to-target $\mathrm{T}_{0}{ }^{(\lambda)}$ (Moral, 1991); $l_{1}=0.0949$ is a constant coefficient; $Q$ is the ratio between upwelling radiance and irradiance (Mobley, 1994). Assuming an isotropic light field, the value of $Q$ is taken as being equal to $\pi$ sr. The constant number 0.54 describes the fraction of transmitted light from below the water surface. $a(\lambda)$ and $b_{b}(\lambda)$ are bulk absorption and backscattering, respectively. At the NIR part of the spectrum, the $\rho_{\mathrm{w}}{ }^{(\lambda)}$ column is assumed to be optically governed by the SPM backscattering $b_{b(S P M)}(\lambda)$ and the water absorption $a_{w}(\lambda)$ coefficients:

$$
a(\lambda)=a_{w}(\lambda)
$$




$$
b_{b}(\lambda)=b_{b(S P M)}(\lambda)=b_{b(S P M)}^{*}(\lambda) \times C_{S P M}
$$

where $b^{*}{ }_{b(S P M)}(\lambda)$ and $C_{s p m}$ are the specific backscattering coefficient and SPM concentration respectively.

\section{RESULTS AND DISCUSSION}

\section{Atmospheric correction}

The lower mean value of $\rho_{\mathrm{w}}{ }^{(4)}$ estimated using the standard approach by Gordon and Wang (1994) is found in the image of 5 May 2010. On this day, SPM concentration values measured by the network were lower and spatially homogeneous $\left(0.102-0.180 \mathrm{~g} \mathrm{~L}^{-1}\right)$. Whereas the mean maximum value of $\rho_{\mathrm{w}}{ }^{(4)}, 0.126$, occurred on 31 March 2009. However, when extending to turbid waters, $\rho_{\mathrm{w}}{ }^{(5)}$ was different from 0 and the mean values of $\rho_{\mathrm{w}}$ both for band 4 and 5 were higher. The mean minimum value of $\rho_{\mathrm{w}}{ }^{(4)}$ on 5 May, 2010, increased to a value of 0.087 compared to that of 0.075 obtained with the standard approach by Gordon and Wang (1994). A mean maximum value of $\rho_{\mathrm{w}}{ }^{(4)}$ of 0.182 and of $\rho_{\mathrm{w}}{ }^{(5)}$ of 0.073 were reached on 31 March 2009. These $\rho_{\mathrm{w}}$ values are much higher than those observed by other authors using this technique for turbid waters (Ruddick et al., 2000). Making a comparative study of the $\rho_{\mathrm{w}}{ }^{(4)}$ results obtained by the standard approach by Gordon and Wang (1994) and that extended to turbid waters, it was observed that the values of the latter were around $30 \%$ higher than those of the former for all the days, both in minima, maxima and means.

Negative values of $\rho_{\mathrm{w}}{ }^{(4)}$ were observed in three images $(0.22 \%$ in the most unfavorable case) but they were removed from the analysis. The existence of negative values is associated with an overestimation of $\rho_{\mathrm{a}}{ }^{(\lambda)}$, which underestimates the values of $\rho_{\mathrm{w}}$ (Mao et al., 2013), or with the existence of deeper waters.

However, the mean values of $\varepsilon_{(4,5)}$ obtained for each of the images do not show the same suitability. On 5 May 2010, the line of fit associated with obtaining a mean value of $\varepsilon_{(4,5)}$ has an $\mathrm{R}^{2}=0.85$, whereas for 19 August 2008 , its $\mathrm{R}^{2}=0.44$. On days on which this trend was observed various areas are differentiated, distinguishing between waters with a low $\rho_{\mathrm{w}}$, corresponding to clear waters, and a high $\rho_{\mathrm{w}}$ corresponding to turbid waters. For each water type we used the corresponding $\varepsilon_{(4,5)}$, thus obtaining for 19 August 2008, a mean $\varepsilon_{(4,5)}$ of 0.533 and mean $\rho_{\mathrm{w}}{ }^{(4)}$ of 0.214 for turbid waters and a mean $\varepsilon_{(4,5)}$ of 1.042 and a mean $\rho_{\mathrm{w}}{ }^{(4)}$ of 0.092 for clear waters.

\section{Deriving optical properties}

It was demonstrated that the application of the Gordon semi-analytical model (1988b) on all the dates was not possible over the whole estuary area. It was necessary to restrict its use to areas in which $\rho_{\mathrm{w}}{ }^{(4)}<0.541_{1} Q$, to prevent negative SPM backscattering coefficients ( $\mathrm{b}_{\mathrm{b}}$ (SPM)). Also, values of $\rho_{\mathrm{w}}{ }^{(4)}$ which although being lower are very close to $0.54 l_{1} Q$ give values of $b_{b}$ (SPM) of a high order of magnitude. In the study area, in which the SPM concentration range is high and varied, there are many areas with high $\rho_{\mathrm{w}}{ }^{(4)}$ which cannot be modelled.

Figure 2 (a) shows the derived $b_{b(S P M)}$ along the estuary on 25 December 2008 for the $90 \%$ of the estuary area. Values of $b_{b}(\mathrm{SPM})$ were observed with a minimum of $0.158 \mathrm{~m}^{-1}$ and a maximum of $13.47 \mathrm{~m}^{-1}$.Large percentage, $83 \%$, of the $\mathrm{b}_{\mathrm{b}}$ (SPM) values were lower than $2 \mathrm{~m}^{-1}$. On days when the SPM concentration was low, the $b_{b(\mathrm{SPM})}$ could be obtained for a larger area, reaching an area of $95 \%$ on 5 May 2010.

Figure 2(b) shows the relationship between SPM measured and derived $b_{b(S P M)}$ coefficients at the CTDs for all the days studied. The image taken on 11 February 2009 has been removed from the study due to the extreme conditions found which are at the limit of the optimum working range of CTDs. A positive linear relationship can be observed on most days, which allows us to estimate SPM concentration. Figure 3 shows the measured versus estimated SPM concentration on four days using a mean value of $\varepsilon_{(4,5)}$ (Fig. 3(a)) and two values (Fig. 3(b)). It is clear that the employment of two $\varepsilon_{(4,5)}$ improves the estimation of the SPM concentration, with better $\mathrm{R}^{2}$ and 
RMSE (see Table 1). On 18 May 2009, $\mathrm{R}^{2}$ varies from 0.68 for the single value solution to 0.86 for the two solution with RMSE of $46 \mathrm{~g} \mathrm{~m}^{-3}$ and $35 \mathrm{~g} \mathrm{~m}^{-3}$ respectively.

a)

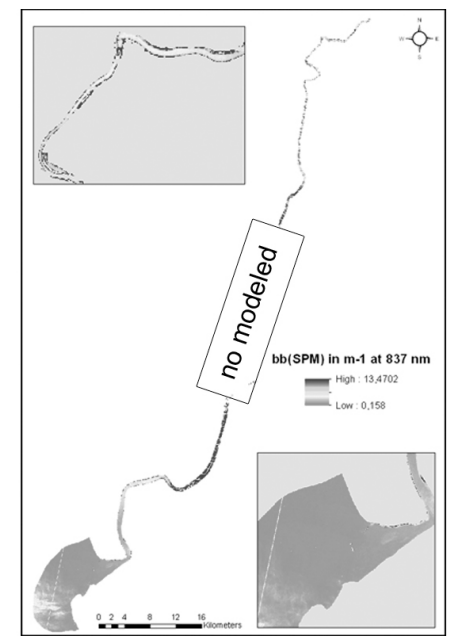

b)

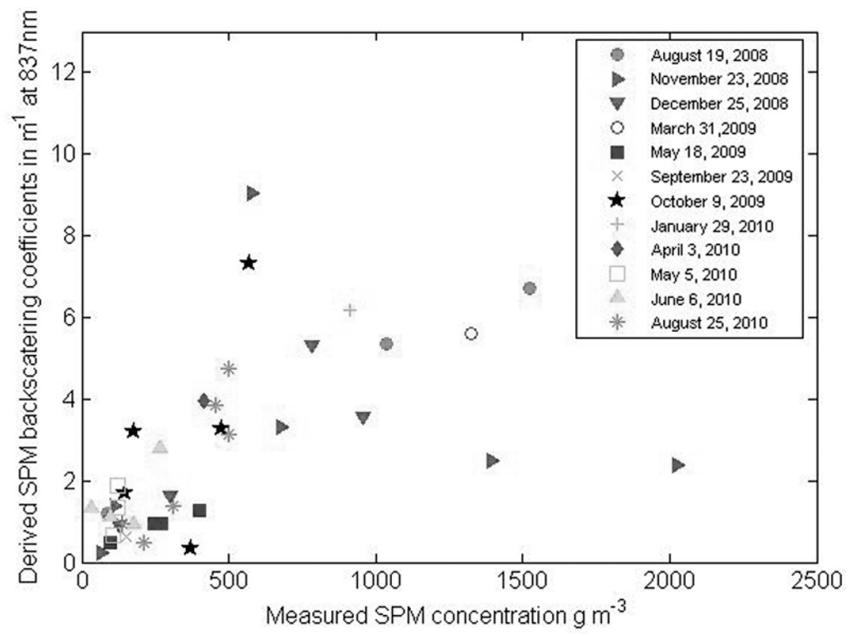

Fig. 2 (a) Derived $b_{b(S P M)}$ at $837 \mathrm{~nm}$ on 25 December2008; (b) measured SPM concentration versus derived $b_{b(\mathrm{SPM})}$ at $837 \mathrm{~nm}$ on all the days studied.

a)

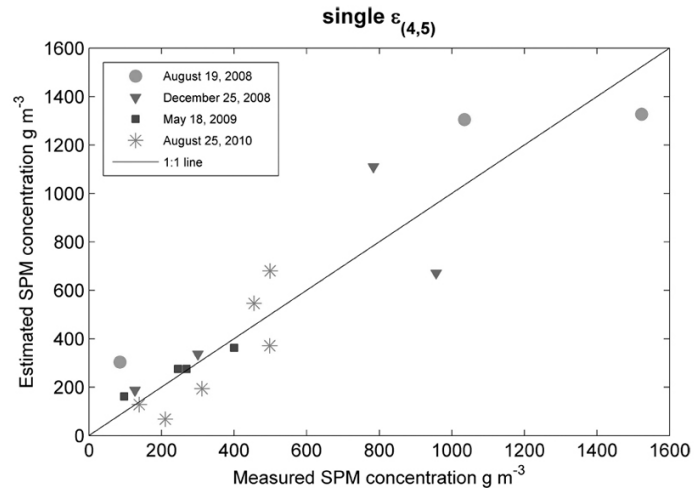

b)

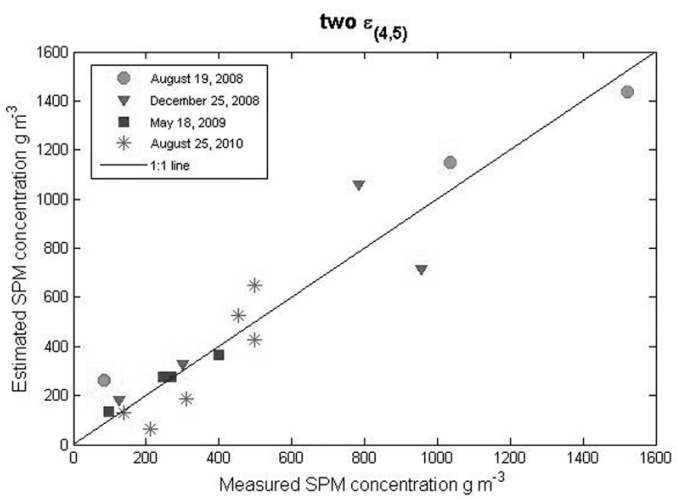

Fig. 3 (a) Measured versus estimated SPM concentration on four days using a single mean value of $\varepsilon_{(4,5)}$; (b) measured versus estimated SPM concentration on four days using two mean value of $\varepsilon_{(4,5)}$

Table 1 Values of $\mathrm{R}^{2}$ and RMSE obtained using a single mean value of $\varepsilon_{(4,5)}$ and two value of $\varepsilon_{(4,5)}$.

\begin{tabular}{lllll}
\hline & Single $\varepsilon_{(4,5)}$ & & Two $\varepsilon_{(4,5)}$ \\
Date & $\mathrm{R}^{2}$ & $\operatorname{RMSE}\left(\mathrm{g} \mathrm{m}^{-3}\right)$ & $\mathrm{R}^{2}$ & $\operatorname{RMSE}\left(\mathrm{g} \mathrm{m}^{-3}\right)$ \\
\hline 19 August 2008 & 0.77 & 282 & 0.93 & 159 \\
25 December 2008 & 0.64 & 253 & 0.73 & 215 \\
18 May 2009 & 0.68 & 46 & 0.86 & 35 \\
25 August 2010 & 0.69 & 135 & 0.75 & 116 \\
\hline
\end{tabular}

\section{CONCLUSIONS}

The standard approach by Gordon and Wang (1994) which assumes that $\rho_{\mathrm{w}}{ }^{(5)}=0$, underestimates the water leaving reflectance at band four $\rho_{\mathrm{w}}{ }^{(4)}$, by approximately $30 \%$ with respect to those obtained when we do not neglect the NIR reflectance.

The semi-analytical model of Gordon (1988b), employed in band 4 to obtain the water's properties, is valid for a range of $\rho_{\mathrm{w}}{ }^{(4)}$, so that $\rho_{\mathrm{w}}{ }^{(4)}<0.54 l_{1} Q$. In this case, with high SPM 
concentrations, it was not possible to apply over the whole study area, and its range was between $80 \%$ and $95 \%$ of the area for the days 19 August 2008 and 5 May 2010, respectively. This fact justifies the need to define new calibration constants for this model which could be adapted to very turbid waters.

The use of two values of $\varepsilon_{(4,5)}$ associated with turbidity level results in a better accuracy in the retrieved SPM values. The use of the two $\varepsilon_{(4,5)}$ approach improves the results as $\mathrm{R}^{2}=0.86$ and $\mathrm{RMSE}=35 \mathrm{~g} \mathrm{~m}^{-3}$ in comparison to $\mathrm{R}^{2}=0.68$ and $\mathrm{RMSE}=46 \mathrm{~g} \mathrm{~m}^{-3}$ of the single $\varepsilon_{(4,5)}$ value.

Acknowledgements The results of this work were carried out as part of the project P09-RNM4735 "Dynamics of suspended solids in estuarine waters" funded by the Ministry of Innovation, Science and Commerce of the Regional Government of Andalusia. Moreover, the present work was partially developed within the framework of the Panta Rhei Research Initiative of the International Association of Hydrological Sciences (IAHS) (Working Group Water and energy fluxes in a changing environment). We would also like to thank Professors W. Verhoef of the Faculty of Geo-Information Science and Earth Observation, University of Twente for his advice.

\section{REFERENCES}

Carder, K., Cattrall, C. and Chen, F. (1999a) MODIS clear water epsilon, Algorithm Theoretical Basis Document ATBD.

Carder, K., et al. (1999b) Semianalytical moderate-resolution imaging spectrometer algorithms for chlorophyll-aand absorption with bio-optical domains based on nitrate-depletion temperature.Journal of Geophysical Research, 104 (C3),5403-5421.

Carpintero, M, et al. (2013) Estimation of turbidity along the Guadalquivir estuary using Landsat TM and ETM+ images.Remote Sensing for Agriculture, Ecosystems and Hydrology 8887, p. 88870B, Dresden, Germany.

Contreras, E. and Polo, M.J. (2012) Measurement frequency and sampling spatial domains required to characterize turbidity and salinity events in the Guadalquivir estuary (Spain).Natural Hazard and Earth System 12, 2581-2589.

Danbara, T. (2014) Deriving eater quality indicators of Lake Tana, Ethiopia, from Landsat-8. Thesis. University of Twente, Netherlands.

Goody, R. (1964) Atmospheric Radiation 1. Theoretical Basis. Oxford University Press.

Gordon, H. (1997) Atmospheric correction of ocean color imagery in the Earth observing system era. Journal of Geophysical Research $102(17), 81-106$.

Gordon, H., Brown, J. and Evans, R. (1988a) Exact Rayleigh scattering calculation for the use with the NIMBUS-7 coastal zone color scanner. Applied Optics 27 (5), 862-871.

Gordon, H., et al. (1988b) A semianalytical radiance model of ocean color. Journal of Geophysical Research 93, 10909-10924.

Gordon, H. and Castano, D. (1987) Coastal zone color scanner atmospheric correction algorithm: multiple scattering effects.Applied Optics 26(11), 2111-2122.

Gordon, H. and Wang, M. (1994) Retrieval of water-leaving radiance and aerosol optical thickness over the ocean with SeaWiFS: a preliminary algorithm. Applied Optics 33 (3), 443-452.

Kuchinke, C., et al. (2009) Spectral optimization for constituent retrieval in case 2 waters ii: Validation study in the Chesapeake Bay. Remote Sensing of Environment 113(3), 610-621.

Malkmus, W. (1967) Random Lorentz band model with exponential-tailed s-1 line intensity distribution function. Journal of Optical Society of America 57(3), 323-329.

Mao, Z., et al. (2013) A new approach to estimate the aerosol scattering ratios for the atmospheric correction of satellite remote sensing data in coastal regions. Remote Sensing of Environment, 132, 186-194.

Mobley, C. (1994) Light and Water Radiative Transfer in Natural Waters. Academic Press.

Morel, A. (1991) Light and marine photosynthesis: a spectral model with geochemical and climatological implications. Progress in Oceanography 36, 263.

Navarro, G., Gutiérrez, F. and Díez-Minguito, M. (2011) Temporal and spatial variability Guadalquivir estuary: a challenge for real time telemetry. Ocean Dynamics 61, 753-765.

Ruddick, K., Ovidio, F. and Rijkeboer, M. (2000) Atmospheric correction of SeaWiFS imagery for turbid coastal and inland waters. Applied Optics 39(6), 897-912.

Salama, M.S., Monbaliu, J. and Coppin, P. (2004) Atmospheric correction of advanced very high resolution radiometer imagery. International Journal of Remote Sensing 25 (7-8), 1349-1355.

Salama, M.S., Radwan, M. and Van der Velde, R. (2012) A hydro-optical model for deriving water quality variables from satellite images (HydroSat): A case study of the Nile River demonstrating the future Sentinel-2 capabilities. Physics and Chemistry of the Earth 50-52, 224-232.

Salama, M.S. and Shen, F. (2010) Simultaneous atmospheric correction and quantification of suspended particulate matters from orbital and geostationary earth observation sensors. Estuarine, Coastal and Shelf Science 86, 499-511.

Wang, M. (1999) Atmospheric correction of ocean color sensors: computing atmospheric diffuse transmittance. Applied Optics $38,451-455$. 